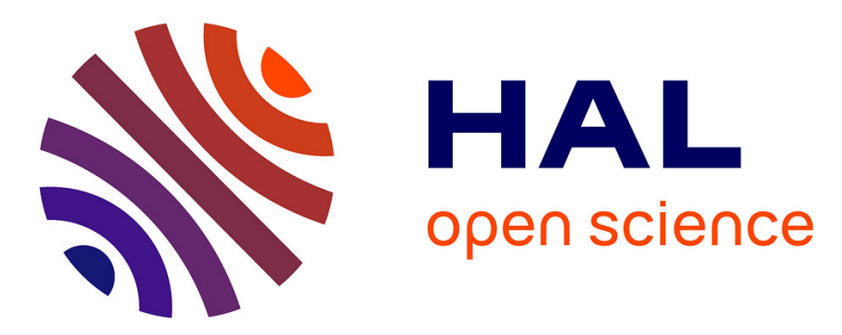

\title{
Martensitic Phase in NiTi and CuAlNi Studied by Isothermal Mechanical Spectroscopy
}

\author{
F. Deborde, V. Pelosin, A. Rivière
}

\section{To cite this version:}

F. Deborde, V. Pelosin, A. Rivière. Martensitic Phase in NiTi and CuAlNi Studied by Isothermal Mechanical Spectroscopy. Journal de Physique IV Proceedings, 1996, 06 (C8), pp.C8-401-C8-404. 10.1051/jp4:1996886 . jpa-00254697

\section{HAL Id: jpa-00254697 https://hal.science/jpa-00254697}

Submitted on 1 Jan 1996

HAL is a multi-disciplinary open access archive for the deposit and dissemination of scientific research documents, whether they are published or not. The documents may come from teaching and research institutions in France or abroad, or from public or private research centers.
L'archive ouverte pluridisciplinaire HAL, est destinée au dépôt et à la diffusion de documents scientifiques de niveau recherche, publiés ou non, émanant des établissements d'enseignement et de recherche français ou étrangers, des laboratoires publics ou privés. 


\title{
Martensitic Phase in NiTi and CuAlNi Studied by Isothermal Mechanical Spectroscopy
}

\author{
F. Deborde, V. Pelosin and A. Rivière \\ Laboratoire de Mécanique et de Physique des Matériaux, URA 863 du CNRS, ENSMA, Site du \\ Futuroscope, BP. 109, 86960 Futuroscope cedex, France
}

\begin{abstract}
Internal friction has been measured in isothermal conditions over a large frequency range $\left(10^{-3} \mathrm{~Hz}-10\right.$ $\mathrm{Hz}$ ) in $\mathrm{NiTi}(49.6 \% \mathrm{Ni})$ and $\mathrm{CuAlNi}(15 \% \mathrm{Al}, 3 \% \mathrm{Ni})$ alloys. After convenient thermal treatments, the samples present a stable martensitic phase between room temperature and $\sim 350 \mathrm{~K}$ for NiTi and $\sim 873 \mathrm{~K}$ for CuAlNi. We have found an increase of $\mathrm{Q}^{-1}$ at very low frequencies which depend on temperature. The activation energy deduced from different spectra is $0.85 \mathrm{eV}$ for NiTi and $0.45 \mathrm{eV}$ for CuAlNi. Other experiments, performed on a $6 \%$ strained NiTi sample, have evidenced a decrease Ea. From these results we have assumed that the damping increase could be associated to the interface motion of the martensite variants. In other words, the high density of the variants in a non strained sample could inhibit their displacements.
\end{abstract}

\section{INTRODUCTION}

The shape memory alloys are commonly considered as high damping materials [1]. However the high. damping capacity is generally only in the martensitic state and of course during the transition. It is well known that this damping depends on the defects concentration and their mobility but it could be related to transient effects too [2]. In order to study more accurately the origin of the different damping contributions, we have performed isothermal internal friction measurements in a very large frequency range for various temperatures.

\section{EXPERIMENTAL PROCEDURE}

Two shape memory alloys have been studied, $\mathrm{Ni} \mathrm{Ti} \mathrm{(49.6} \mathrm{at} \mathrm{\%} \mathrm{Ni)} \mathrm{and} \mathrm{CuAlNi}(12 \%$ wt $\mathrm{Al}$ and $3 \% \mathrm{wt} \mathrm{Cu}$ ). The samples were cut in flat bar of typical dimensions: $50 \times 6 \times 1 \mathrm{~mm}^{3}$. The samples were initially annealed for ten hours at $800^{\circ} \mathrm{C}$ then furnace cooling. The characteristic transformation temperatures for the NiTi specimen measured by DSC are $\mathrm{Ms}=350 \mathrm{~K}, \mathrm{Mf}=325 \mathrm{~K}, \mathrm{As}=370 \mathrm{~K}$ and $\mathrm{Af}=385 \mathrm{~K}$. Concerning the $\mathrm{CuAlNi}$, a preliminary thermal treatment has been done so as to stabilized the martensite phase in a large range of temperature (As> 573K). Internal friction measurements were carried out with an inverted tortional pendulum subjected to subresonant forced vibrations with a $5.10^{-6}$ torr vacuum. The apparatus allows isothermal damping measurements over a large frequency range $\left(10^{-4} \mathrm{~Hz}\right.$ to $\left.10 \mathrm{~Hz}\right)$ with ten discrete frequencies per decade. $Q^{-1}$ is then calculated from the determination of tan $\phi$ where $\phi$ is the phase angle between the applied stress and the resulting strain.

\section{RESULTS}

\subsection{Non strained NiTi alloy}

Figure 1 shows the internal friction evolution versus frequency measured on heating at $293 \mathrm{~K}, 333 \mathrm{~K}, 353 \mathrm{~K}$ and $367 \mathrm{~K}$ in the martensitic state as well as two spectra measured in the austenitic phase $383 \mathrm{~K}$ and $418 \mathrm{~K}$. As it has been exposed elsewhere [3] the stabilization of the martensite when it was heated or cooled is very long. It's the reason why all the spectra where realized after a $27 \mathrm{~h}$ maintain at each temperature. First, 
it could be checked that the damping is lower in the austenitic phase than in the martensitic one [4]. On the other hand, for every temperature the damping level increases at low frequency. As it could be observed on the martensite spectra, the higher is the temperature of measurements the sharper is the damping growth. For the $367 \mathrm{~K}$, spectra, indeed, the increase begins before $10^{-1} \mathrm{~Hz}$ and reaches an amplitude of more than $40.10^{-4}$ while at $293 \mathrm{~K}$ it only begins at $10^{-2} \mathrm{~Hz}$ for a total amplitude of a few $10^{-4}$. In the austenitic phase, $\mathrm{Q}^{-}$ ${ }^{1}$ increases also with temperature but steadily and much lower in all the frequency range. Furthermore, the two temperature spectra are superimposed.

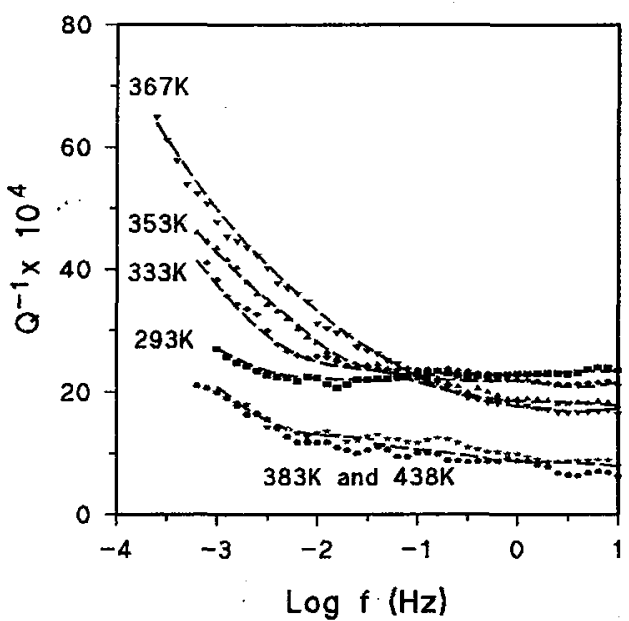

Figure 1. Isothermal internal friction versus frequency measured at various temperatures in the martensitic phase $(293 \mathrm{~K}, 333 \mathrm{~K}, 353 \mathrm{~K}$ and $367 \mathrm{~K})$, and the austenitic phase (383K and 438K).

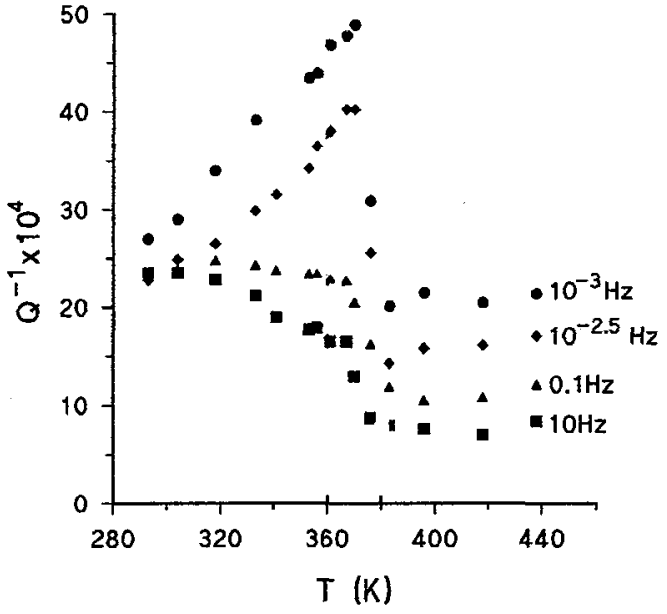

Figure 2. Internal friction measured in isothermal condition and plotted for four frequencies from $10 \mathrm{~Hz}$ to $10^{-3} \mathrm{~Hz}$.

On the figure 2 , the internal friction measured at various temperatures between $293 \mathrm{~K}$ and $418 \mathrm{~K}$ has been reported for four characteristic frequencies, $10 \mathrm{~Hz}, 0.1 \mathrm{~Hz}, 0.032 \mathrm{~Hz}$ and $0.001 \mathrm{~Hz}$. For a better comprehension the temperatures As and Af, determined by DSC, are also indicated. It is clear that the damping hardly depends on the frequency for all spectra, more particularly, $Q^{-1}$ growths up sharply with temperature when the frequency is lower than $10^{-2} \mathrm{~Hz}$ whereas it declines for the 0.1 and 10 spectra. The new point stressed by these results is that the low frequency increase occurred in all the martensitic domain until a temperature located between As and Af. Consequently, we could assume that the damping effect exists as long as the volumic fraction of martensite is large enough.

\subsection{Strained NiTi sample}

In order to study the incidence of a pseudo plastic deformation, that is to say the orientation of the martensite variants, we have performed the same experiment as previously on a $6.2 \%$ (longitudinally) strained sample. The figure 3 reports the behavior of internal friction measured at different temperatures for three typical frequencies. The full symbols correspond to the first heating after straining. In that case the low frequency damping is much higher at low temperature, and increases slowly on heating. As a consequence, the damping measured around the transition is quite similar to the one of a non strained sample (dashed line). Concerning the high frequency spectrum $(10 \mathrm{~Hz})$, there is no significant difference between the two samples. As a result, for the strained sample, the low frequency increase is revealed until the low temperatures. Incidentally, we can notice that the transition occurs at higher temperature comparatively to the non strained sample. This is explained by the fact that the oriented martensite is supposed to be stable in a larger range of temperature [5].

Then, the strained sample has been submitted to a first transition cycle, the measurements obtained on cooling are also reported on figure 3 (open symbols). With the occurrence of the transition, the strain effect 
is suppressed. That is the reason why the measurements realized on cooling are superimposed to the ones obtained on the first sample (dashed line).

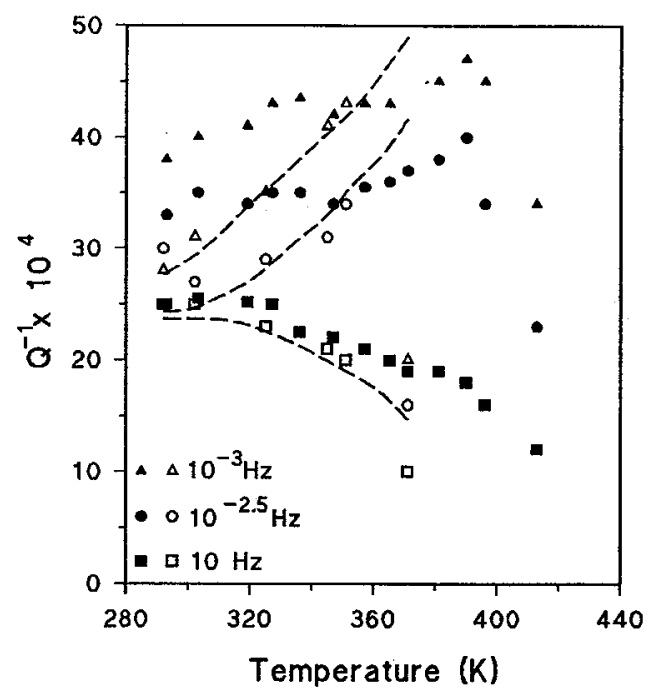

Figure 3. Isothermal damping measured on a strained sample The full symbols correspond to the first heating, the open symbols are relative to the second heating (after a cycle to $450 \mathrm{~K}$ ) and the dashed line indicates the damping of a non strained sample.

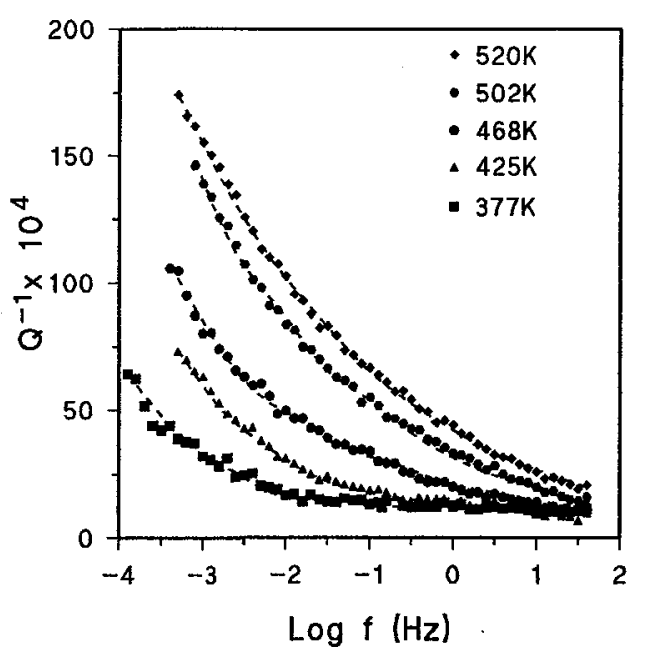

Figure 4. Isothermal internal friction versus frequency measured at various temperatures in the martensitic phase $(377 \mathrm{~K}, 425 \mathrm{~K}, 468 \mathrm{~K}, 502 \mathrm{~K}$ and $520 \mathrm{~K})$ of a CuAlNi sample.

\subsection{Isothermal measurements on martensitic CuAINi}

As the low frequency damping effect seems to be essentially linked to the martensite variants we have performed the same experiment on a CuAlNi sample. In this case the martensite is stabilized on a large range of temperature so we can study the effect at much higher temperature. The results obtained on isothermal condition are reported on figure 4 . Once again the low frequency increase is checked with the same characteristics than previously.

\section{DISCUSSION}

Up to now the rising of damping at low frequency has never been studied. We assume that it is related to the martensite variant motions. The Schoeck model [6], which take into account a viscoelastic behavior of the material seems to be quite well suitable. The dependence of $Q^{-1}$ on $\omega$ and $T$ may then be expressed by:

$$
Q^{-1}=K\left[\omega \exp \left(E_{a} / k T\right)\right]^{n}
$$

As $\mathrm{K}$ is an unknown constant, we have to plot $\ln \left(Q^{-1}-Q^{-1}{ }_{0}\right)$ versus $\ln \omega$, in order to determine the preexponential factor, $n,\left(Q_{0}^{-1}\right.$ is the stable background measured at high frequency). Then the determination of $\mathrm{Ea}$ is made by the slope of the curve $\left(\ln \mathrm{Q}^{-1}-\mathrm{Q}^{-1}{ }_{0}\right)-\mathrm{n} \ln \omega$ versus $1000 \mathrm{n} / \mathrm{T}$. The experimental determination is the same for all samples but it has been detailed for the non strained NiTi on figures 5 and 6. The results obtained for Ea are summarized below:

\begin{tabular}{|l|c|c|c|}
\hline Sample & non strained NiTi & $6.2 \%$ strained NiTi & CuAlNi \\
\hline Ea & $0.85 \mathrm{eV}$ & $0.3 \mathrm{eV}$ & $0.45 \mathrm{eV}$ \\
\hline
\end{tabular}




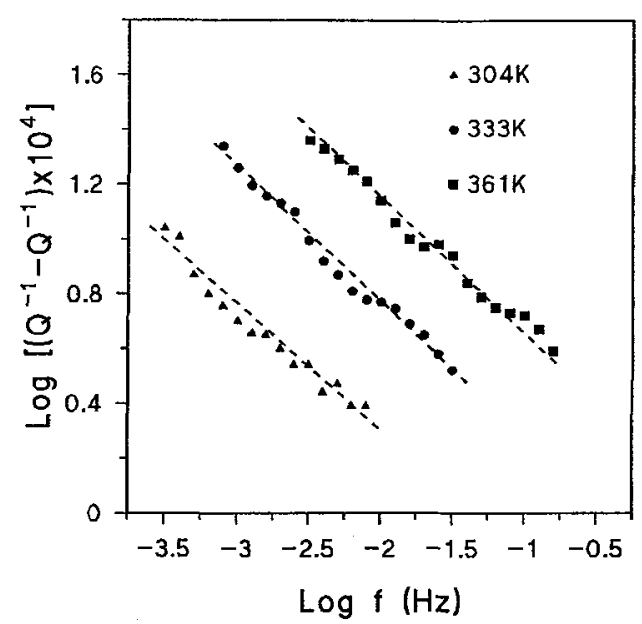

Figure 5. (In $\mathrm{Q}^{-1}-\mathrm{Q}^{-1}$ ) plotted versus in (frequency) in order to determine $\mathbf{n}$.

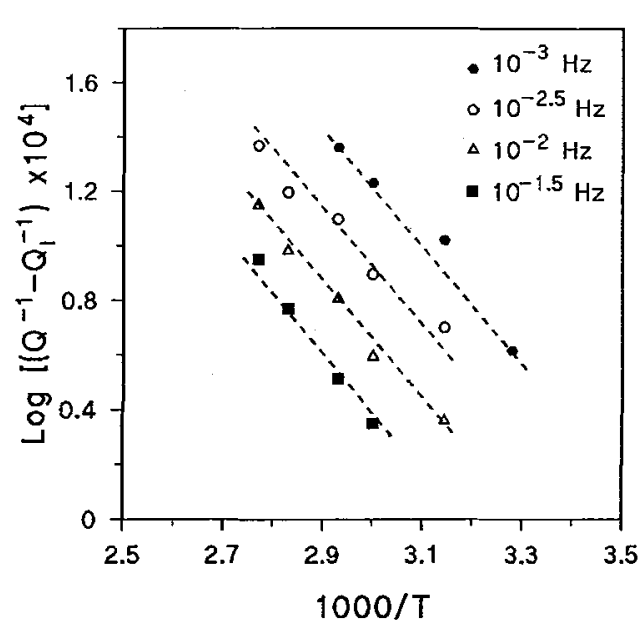

Figure 6. (In $\mathrm{Q}^{-1}-\mathrm{Q}^{-1}{ }_{0}$ ) plotted versus $1000 / \mathrm{T}$ so as to deduced Ea.

If we compare the two NiTi samples it becomes clear that the activation energy calculated on the strained sample is much lower than the one of the non strained. The structural difference between the two specimens consists on the orientation of the martensite variants and probably on the density of dislocations. Indeed, in the $6.2 \%$ sample the variants oriented following the applied stress has been favoured to the detriment of the others. Furthermore, dislocations have been introduced by straining the material. All these microstructural modifications seem to vanish with the austenite formation, and of course doesn't reappear on cooling back. However an $367 \mathrm{~K}$ anneals looks quite low to eliminate the straining dislocations. In this respect, everything leads to the conclusion that the low frequency increase is linked to the variant (and not to the dislocation) density. The more are the variants and the higher is the activation energy. Two explanations could be proposed. The damping effect is either directly due to the variant displacement, either as it has been suggest by Gottahardt and Mercier [4] the high damping is mainly explained by the motion of interface dislocations (and only theses types of dislocations).

\section{CONCLUSION}

To sum up on the main characteristics of the low frequency increase we could state that the effect occurs when the sample is in martensitic phase (even partially) on at least two different alloys. The effect is more pronounced on a strained sample at low temperature and the calculated activation energy is lower. The heating of the sample just above Af is enough to give the internal friction similar to the one of the non strained sample so that the contribution of the bulk dislocation motions has been dismissed. It would appear then that the low frequency increase is due to movements located at the interfaces, that is to say, variant or dislocation motions.

\section{References}

[1] J. Van Humbeeck, J. Stoiber, L.Delaey and R. Gotthardt, Z. Metallkd, 86, (1995), 176-183

[2] J. S. Zhu, R. Schaller and W. Benoit, Phys. Stat. Sol. (a) 108, (1988), 613-618

[3] F. Deborde, V. Pelosin and A. Rivière, Scripta Met, 33, (1995), 1993-1998

[4] R. Gotthardt and O. Mercier, J. de Phys., 10, (1981), C5-995-1000

[5] S. Miyazaki, Y. Igo and K. Otsuka, Acta Metall. 34, (1986), 2045-2051

[6] G. Schoeck, E. Bisogni and J. Shyne, Acta Met., 12, (1964), 1466-1468 